\title{
Nursing Intervention for Improving Mothers' Care regarding their Preschool Children with Otitis Media
}

\section{Basma Mahmoud Ahmed ${ }^{1}$, Hanaa Abd El Gawad Abd El Megeed ${ }^{2}$ and Amina Abd Elrazek Mahmoud $^{3}$}

(1) Nursing specialist, Central Hospital of Kafr Shokr, EL Qalubia Governorate, (2) Professor of Community Health Nursing, Faculty of Nursing, Benha University and (3) Assistant professor of Community Health Nursing, Faculty of Nursing, Benha University

\begin{abstract}
Background: Otitis media is one of the most common childhood infections in pre-school aged children and a major cause of childhood morbidity. This study aimed to evaluate the effect of nursing intervention for improving mothers' care regarding their preschool children with otitis media. Research design: A quasi-experimental design was used. Setting: The study was conducted at the outpatient hearing clinic of Benha Specialized Children Hospital. The sample: A simple random sample was used, it included 100 preschool children. Two tools were used I: A structured interviewing questionnaire to assess; a) socio-demographic characteristics of the studied mothers and preschool children, b) medical history of preschool children, c) mothers' knowledge regarding Otitis Media, d) Mothers' reported practices regarding care of their preschool children with otitis media. II: Observational checklist to assess the practices of mothers on how to care for their children with Otitis Media. Results: More than half of the studied mothers aged 20 to less than 30 years, more than three fifths had university education, more than three fifths had good total knowledge while more than three quarters had satisfactory total practices. Conclusion: The nursing intervention succeeded in improving the studied mothers' knowledge and practices regarding care of their preschool children with otitis media.Recommendations: The study recommended availability of simplified and comprehensive Arabic booklet that deals with improving mothers' care knowledge regarding their preschool children suffering from otitis media and also further researches should be conducted for preschool children with other health problems.
\end{abstract}

Key words: Otitis Media, Preschool Children, Mothers care, nursing intervention.

\section{Introduction:}

Otitis Media (OM) is one of the most common childhood infections in pre-school aged children and a major cause of childhood morbidity. OM also represents the most frequent reason why children are prescribed with antibiotics or undergo surgery in the developed countries. Moreover, in most of the countries belonging to developing countries, no guidelines regarding the use of antibacterial treatment in $\mathrm{OM}$ and respiratory tract infections exist and in several countries, parents can purchase any antibacterial drug in pharmacies without mandatory medical prescriptions (Saad et al., 2020).

Otitis media subdivided into several types; Acute Otitis Media (AOM), recurrent AOM, $\mathrm{OM}$ with Effusion (OME) and Chronic Suppurative Otitis Media (CSOM). AOM presents with local and systemic signs and it has a rapid onset, and is a leading cause of antibacterial treatment hazards of children. OME can occur during the resolution of AOM once the acute inflammation has resolved but 
bacteria may still be present, while CSOM requires ongoing inflammation of the middle ear leading to otorrhea persisting for at least two weeks and perforation of the tympanic membrane (Kono et al., 2021).

Otitis media, especially in children, can result in physical and social disability. If the infection is left untreated, two kinds of complications may occur: intra-temporal, and intracranial complications all of which require surgical interference. The most common intra-temporal complication is mastoiditis, which is characterized by the spread of the bacterial colonization into the mastoid air cells, causing local destruction. Mastoiditis manifests in fever, suppuration, and painful swelling around the region of the mastoid process of the temporal bone. In the preantibiotic era, untreated mastoiditis could be life-threatening, as the infection could affect the endocranium (Busom et al., 2021).

Mothers of preschool children suffering from Otitis Media play an important role in managing and providing care for their children as care givers; giving medications as ear drops and prescribed antibiotics. They also can provide ear care by cleansing the ear canal by sterile cotton cones moistened with physiologic saline or hydrogen peroxide, then the ear is wiped dry with sterile cotton, and apply a warm, moist washcloth on child's ear to decrease pain and reduce swelling (Espahbodi et al., 2020).

Community Health Nurse (CHN) plays an essential role for applying the principles of primary, secondary and tertiary prevention for optimizing the maximal physical, psychological, mental and social health for the community at all. First; through intervening at the peer group level through educational programs, alternative recreational activities and peer counseling is most effective. Second; coaching in values clarification, social skills and assurance help to give the skills to cope with situation .Third; assistance is a program that uses team efforts by teachers, parents, community leaders. Programs help by building selfconcept, putting positive examples and working to include in the community activities ( Abraham, 2019).

Significance of the study:

According to the (World Health Organization, 2019): approximately 42 million people over the age of three years suffer hearing loss due to otitis media. Approximately $90 \%$ of children experience this disorder before they enter the school system. Many attacks of otitis media spontaneously resolve within three months, but in $30 \%$ to $40 \%$ of children, the disorder becomes recurrent. Otitis media occurs in $75 \%$ of children at least three times in their first three years of life.

Recently in developing countries around 20,000 children die annually from complications associated with OM, with the highest mortality rates in children $<5$ years of age. In Egypt, $10.8 \%$ of children from three years to five years suffering from otitis media, also otitis media with effusion is a highly prevalent disease in young children under six years and one of the most significant causes of hearing loss in children (Saad et al., 2020).

\section{Aim of the study:}

The study aimed to evaluate the effect of nursing intervention for improving mothers' care regarding their preschool children with otitis media through:-

1- Assessing knowledge of mother about otitis media.

2- Assessing practices of mothers about care of their children suffering from otitis media.

3- Developing and implementing a nursing intervention for mothers' of preschool children with otitis media. 
4- Evaluating a nursing intervention for mothers' of preschool children with otitis media.

\section{Research Hypothesis}

The nursing intervention will improve mothers' knowledge and practices regarding their children with otitis media.

\section{Subjects and method:}

\section{Research design}

A quasi-experimental design was utilized in this study.

Setting: The study was conducted at outpatient hearing clinic of Benha Specialized Children Hospital.

\section{Sampling:}

A simple random sample of mothers' of preschool children with Otitis Media who attended to the above mentioned setting with inclusion criteria (free from any chronic diseases, free from any handicaps, free from any ear surgery) from the beginning of the study. The total numbers of preschool children attending the above mentioned setting are (400) children per year. The sample included $(25 \%)$ of preschool children in the above mentioned setting who were (100) preschool children.

Tools for Data Collection: Two tools were used for data collection:

\section{The first tool: A structured interviewing} questionnaire: It was developed by the researcher based on literature review of the current and past available national and international references related literature about otitis media disease by using a journal, textbooks and internet search, approved by supervisors and it was written in simple clear Arabic language: It comprised of four parts to assess:

Part 1 included:
A- Socio demographic data about the mothers involved in the study. It included 6 questions e.g; mothers 'age, educational level, marital status, occupation, income, and place of residence.

B- Demographic data about the preschool children. It included 4 questions: Age, sex, birth order, and the child is enrolled in nursery.

Part 2 included: Medical history of preschool children which included 5 questions e.g; hospital admission due to respiratory infection, child' previous attack of otitis media, If yes, child age at the first attack (The onset of $\mathrm{OM}$ ), and duration of otitis media complain.

Part 3 included: Mothers knowledge regarding care of their preschool children with otitis media which included 11 questions.

Part 4 included: Mothers' reported practices regarding care of their preschool children with otitis media which included 4 questions.

\section{Scoring system:}

The scoring system for mothers knowledge was calculated as follows (2) score for complete correct answer, while (1) score for incomplete correct answer, and (0) for don't know answer. For each section of knowledge, the score of the items was summed - up and the total divided by the number of the questions, giving a mean score of the part. These scores were converted into a percent score. The total knowledge score $=15$ point was considered good if the score of the total knowledge $\geq 75 \%$ (11) point, while considered average if it equals $50-75 \%(8-11)$ point, and considered poor if it is $<50 \%$ equal or less(8) points.

\section{The second tool:}

Observational checklist sheet to assess the practices of mothers' care for their children with otitis media which included (8) questions about: Dealing with pain associated with otitis 
media (three practices), dealing with wax and secretions in the child's ear (three practices), care of the ear tube (two practices), prevention of external ear sores as a complication of the presence of an ear tube (two practices), treatment (three practices), steps of give the child an ear drop (seven practices), care of the affected child's ear during the shower (three practices), removing water in the ear (six practices).

\section{Scoring system}

The scoring system for mothers practices were calculated as follows (1) score for done and (0) for not done. The score of the items was summed - up and the total divided by the number of the items, giving a mean score. These scores were converted into a percent score. The total practices score $=8$ points were considered satisfactory if the score of the total practices $\geq 60 \%$ ( $\geq 5$ points), while considered unsatisfactory if it is $<60 \%$ $(<5$ points).

\section{Content validity of the tools:}

Content validity of the tools was done by four of Faculty's Staff Nursing experts from the Community Health Nursing Specialties who reviewed the tools for clarity, relevance, comprehensiveness, and applicability and give their opinion.

\section{Reliability of the tools:}

Reliability of the tool was applied by the researcher for testing the internal consistency of the tool, by administration of the same tools to the same subjects under similar condition on one or more occasion. Answers from repeated testing were compared (test-re-test reliability). The reliability was done by Cronbachs Alpha Coefficient test which revealed that each of the two tools consisted of relatively homogenous items as indicated by the moderate to high reliability of each tool. The internal consistency of knowledge was 0.93 , and 0.83 for practice.

\section{Ethical consideration:}

All ethical issues were assured; oral consent has been obtained from each mother before conducting the interview and given them a brief orientation to the purpose of the study. They were also reassured that all information gathered would be confidentially and used only for the purpose of the study. The mothers had right to withdraw from the study at any time without giving any reasons.

\section{Pilot study:}

The pilot study was conducted on $10 \%$ (10 mothers) of the study sample to test the content, clarity, applicability, and simplicity of the tools using the interviewing questionnaire and the observational checklist as a pre-test sheet. According to the results obtained from data analysis: items correction, modification, omission and addition were done as needed.

\section{Field work:}

The study was carried out over a period of twelve months from the beginning of October 2019 to the end of September 2020, the data was collected from mothers through interview after taking their acceptance to participate in the study and explaining the aim of the study. The researcher was attended two days/week for the outpatient hearing clinic from $9.00 \mathrm{am}$ to $1.00 \mathrm{pm}$ with application of sessions each session took about 30 to 45 minutes.

The researcher implemented the intervention through three phases as the following:

\section{Implementation phase:}

The interviewing questionnaire conducted by the researcher for data collection in the selected setting, after getting the necessary official permission; the researcher introduced herself and asked the questionnaire used simple Arabic language. Implementation of nursing intervention done through sessions. 
The expected duration of each session was from 30 to 45 minutes, used group discussion also booklet utilized, with clearance of general and specific objectives as follow:

\section{General objectives:}

By the end of nursing intervention, the mothers acquired knowledge, skills about care of their preschool children with otitis media.

The intervention was done through 7 sessions; each session lasted 30-45 minutes and immediately did the post-test.

First session: At the beginning of the first session, the researcher welcomes and introduce herself to the mothers, an orientation to the intervention and its process were presented, anatomy of ear, definition and function of middle ear, taking into consideration the use of simple language according to the educational level.

Second session: Covered definition of otitis media and types of otitis media.

Third session: Covered causes of otitis media, and the most influencing factors of otitis media.

Fourth session: Covered signs and symptoms of otitis media, and complications of otitis media.

Fifth session: Covered care of a child with otitis media, and take care of the child after having an eardrum incision.

Six sessions: Covered the steps to take care of ear pain, and how to deal with wax in the ear.

Seventh session: Covered how to prevent recurrent of otitis media, and when the mothers should go to the doctor?

Discussion, motivation and reinforcement during session were used to enhance learning. Each session started by summary about the previous session and objectives of new topics. Direct reinforcement in the form, a copy of the illustrated booklet with picture about otitis media and its control and prevention was given as a gift for each mother to use it as future reference. At the end of each session, mothers participated in a discussion to correct any misunderstanding. Also, they were informed about the time of next session.

\section{Teaching methods:}

All mothers received the same intervention content using the same teaching methods, there were:

- Lectures/ discussions.

- Demonstration / re- demonstration.

- Presentation.

Teaching aids:

Suitable teaching aids were specially prepared for intervention, as follow: booklets, pictures, and handout

\section{Evaluation phase:}

Evaluation of nursing intervention was done immediately after the end of the nursing intervention by using the same pre/ post test questions.

\section{Statistical analysis:}

The collected data were organized, tabulated and analyzed using appropriate statistical test. The data were analyzed by using the Statistical Package for Social Science (SPSS), that was used to calculate frequencies and percentages mean and standard deviation, also statistical significance and associations by using Chi-square test, it was a test used to study association between two qualitative variables and matrix correlation to detect the relation between the variables for ( $p$ value).

Significance levels were considered as follows:

Highly significance (HS) $\quad \mathrm{p}<0.001$

Significance (S)

$\mathrm{p}<0.05$

Not significant (NS) $\quad \mathrm{p}>0.05$ 


\section{Result:}

Table (1): Shows that; $53 \%$ of the studied mothers aged 20 years and less than 30 years. $65 \%$ had university education. $82 \%$ were married. $62 \%$ were work. $61 \%$ had just enough income, and $88 \%$ of them were from the rural area.

Table (2): Shows that; $52 \%$ of the studied children aged 3 years and less than 4 years, $61 \%$ were male, $40 \%$ were second birth order, and $63 \%$ of them were enrolled in nursery.

Figure (1): Illustrates that; $9 \%$ of the studied mothers had good total knowledge regarding otitis media pre intervention. However, this percent increased post intervention to $63 \%$,
$34 \%$ of them had poor knowledge pre intervention which decreased post intervention to $6 \%$.

Figure (2): Shows that; $47 \%$ of the studied mothers had satisfactory total practices score regarding care of their children with otitis media pre intervention, while post intervention increased to $79 \%$.

Table (3): shows that; there were highly statistically significant correlation between the studied mothers total practices and total knowledge during pre and post intervention $(\mathrm{P}<0.001)$.

Table (1): Frequency distribution of the studied mothers regarding their socio demographic characteristics $(n=100)$.

\begin{tabular}{|c|c|c|}
\hline Demographic characteristics & No. & $\%$ \\
\hline \multicolumn{3}{|l|}{ Age } \\
\hline$<20$ years & 0 & 0.00 \\
\hline $20-<30$ years & 53 & 53.0 \\
\hline $30-<40$ years & 41 & 41.0 \\
\hline $40+$ & 6 & 6.0 \\
\hline \multicolumn{3}{|c|}{$32.47 \pm 3.32$} \\
\hline \multicolumn{3}{|l|}{ Educational level } \\
\hline No read and write & 7 & 7.0 \\
\hline Basic education & 4 & 4.0 \\
\hline Intermediate education & 24 & 24.0 \\
\hline University education & 65 & 65.0 \\
\hline \multicolumn{3}{|l|}{ Marital status } \\
\hline Married & 82 & 82.0 \\
\hline Divorced & 14 & 14.0 \\
\hline Widowed & 4 & 4.0 \\
\hline \multicolumn{3}{|l|}{ Occupation } \\
\hline Working & 62 & 62.0 \\
\hline House wife & 38 & 38.0 \\
\hline \multicolumn{3}{|l|}{ Income/ month } \\
\hline Sufficient and saving & 14 & 14.0 \\
\hline Enough only & 61 & 61.0 \\
\hline Not enough & 25 & 25.0 \\
\hline \multicolumn{3}{|l|}{ Residence } \\
\hline Rural & 88 & 88.0 \\
\hline Urban & 12 & 12.0 \\
\hline
\end{tabular}


Table (2): Frequency distribution of the studied children regarding their demographic characteristics $(n=100)$.

\begin{tabular}{|c|c|c|}
\hline Demographic characteristics & No. & $\%$ \\
\hline \multicolumn{3}{|l|}{ Age/ year } \\
\hline $3-<4$ years & 52 & 52.0 \\
\hline $4-<5$ years & 10 & 10.0 \\
\hline $5-<6$ years & 38 & 38.0 \\
\hline \multicolumn{3}{|l|}{ Mean \pm SD } \\
\hline \multicolumn{3}{|l|}{ Sex } \\
\hline Male & 61 & 61.0 \\
\hline Female & 39 & 39.0 \\
\hline \multicolumn{3}{|l|}{ Birth order } \\
\hline First & 33 & 33.0 \\
\hline Second & 40 & 40.0 \\
\hline Third & 17 & 17.0 \\
\hline Forth and more & 10 & 10.0 \\
\hline \multicolumn{3}{|l|}{ The child is enrolled in nursery } \\
\hline Yes & 63 & 63.0 \\
\hline No & 37 & 37.0 \\
\hline
\end{tabular}

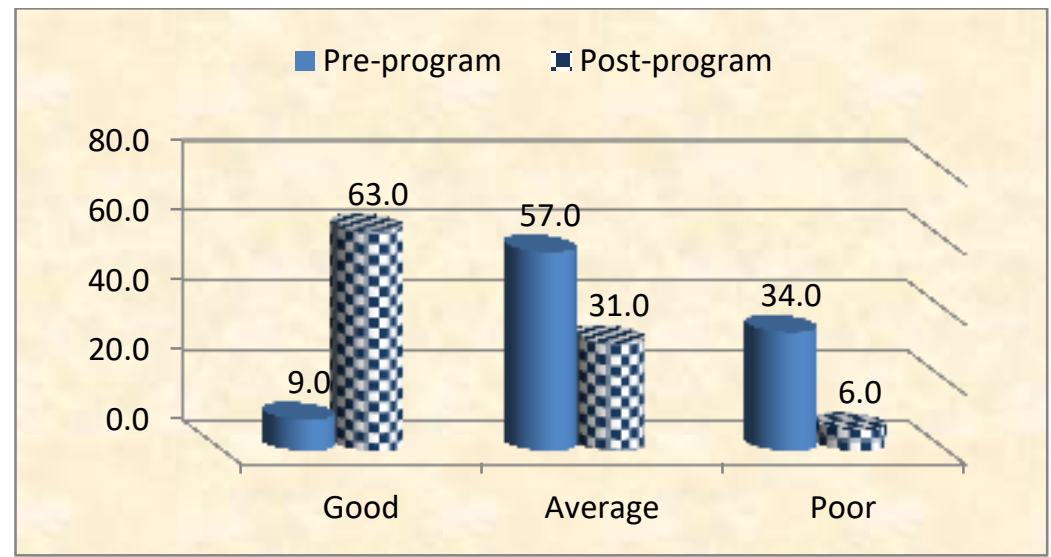

Figure (1): Percentage distribution of the studied mothers' total knowledge score pre and post intervention regarding otitis media $(n=100)$

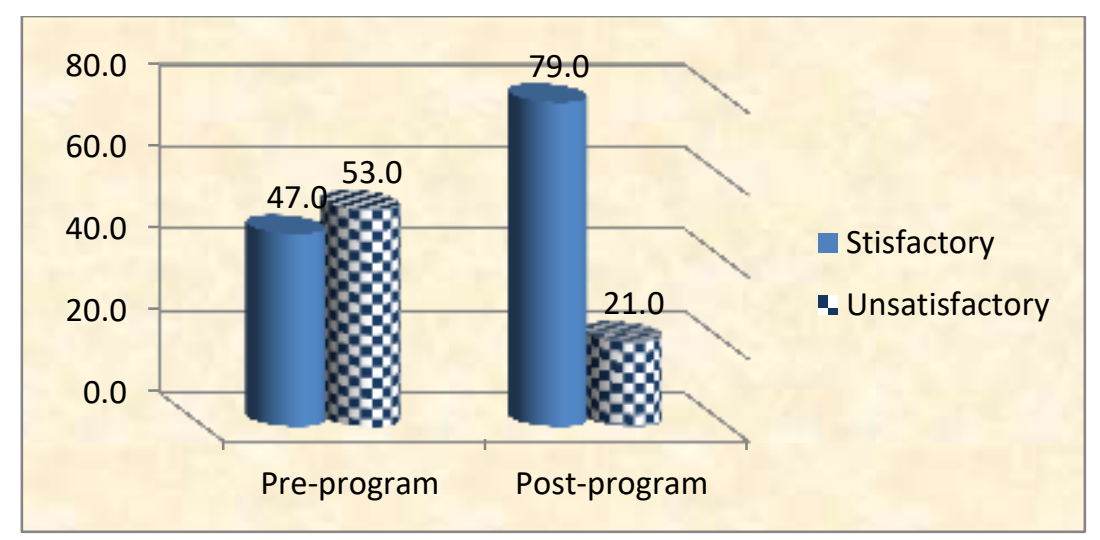

Figure (2): Percentage distribution of studied mothers' total practices regarding care of their children with otitis media pre and post intervention $(n=100)$ 
Table (3): Correlation between total knowledge and total practices among studied mothers pre and post intervention $(n=100)$

\begin{tabular}{|l|l|l|l|l|}
\hline \multirow{4}{*}{ Total practices } & \multicolumn{3}{l|}{ Total knowledge } \\
\cline { 2 - 5 } & Pre & R & Post \\
\cline { 2 - 5 } & $\mathbf{R}$ & p-value & $\mathbf{R}$ & p-value \\
\cline { 2 - 5 } & $\mathbf{0 . 8 2}$ & $\mathbf{0 . 0 0 0 * *}$ & $\mathbf{0 . 7 2}$ & $\mathbf{0 . 0 0 0 * *}$ \\
\hline
\end{tabular}

** Highly statistically significant difference $(\mathrm{p}<0.001)$

\section{Discussion:}

This study aimed to evaluate the effect of nursing intervention for improving mothers' care regarding their preschool children with otitis media through; assessing knowledge of mother about otitis media, assessing practices of mothers about care of their children suffering from otitis media, developing and implementing a nursing intervention for mothers' of preschool children with otitis media, and evaluating a nursing intervention for mothers' of preschool children with otitis media.

According to socio demographic characteristics of the studied mothers; the current study revealed that the sample was consisted of 100 mothers of preschool children, their age ranged from $<20$ to 40 and more years old with mean \pm SD $(32.47 \pm 3.32)$. More than half of them aged between $20-<$ 30 years, and the majority of them were married and from rural area. These results were in the same line with Elsayed (2018) who performed a study of "assessment of mother's knowledge and practices regarding care of their children with otitis media" on 100 mothers in Tanta, who reported that the age of mothers was between $20<30$ years and the majority of them were married and from rural area.

As regards educational level and occupation. This study revealed that; more than three fifths of them had university education and were working. These findings were in agreement with Byeon (2019) who studied " The association between allergic rhinitis and otitis media: A national representative sample in South Korean children " and reported that, three fifths of mothers had university education and work.

Regarding income of the studied sample. The present study revealed that; more than three fifths of them had just enough income. This finding was in the same line with Mohamed (2019) who performed a study of "the impact of an educational program for mothers of children with otitis media on the prevention of its recurrence at Zagazig University Hospital" and reported that, more than three fifths of mothers had enough income.

Regarding the demographic characteristics of the studied children. The present study revealed that; more than half of the studied children aged between $3-<4$ years. These results were in the same line with El-Tohamy (2017) who performed a study of "Assessment of mothers' practice of knowledge about care of their children suffering from otitis media with the view to develop health education module", the study applied to 127 mothers in Mansoura and reported that, more than three quarters of studied children their age was ranged from less than 3 years to less than four years. This is might be due to the functionally and structurally maturation of Eustachian tube 
improved and reaching normal adult length by the age of 7 years.

According to child's gender, the present study shows that; more than three fifths of the studied children were males. This finding was similar to results of study done by Tikaram et al., (2019) who performed a study of "prevalence and risk factors associated with otitis media with effusion in children visiting tertiary care center in Malaysia" who found that more than three fifths of studied children were males. This result comes in disagreement with Abdelazim et al., (2020) who performed a study of "prevalence and associated socio-demographic factors of chronic suppurative otitis media among rural primary school going children in Bangladesh" and reported that, girls are more affected than boys with otitis media.

The present study shows that, more than three fifths of the studied children enrolled in nursery. This finding supported by Hardani et al., (2020) who stated in their study about "pediatric drugs, acute otitis media in children: association with day care centers antibacterial resistance, treatment, and prevention" in Ahvaz that, there was a strong association between otitis media among children and the time they spent outside house, especially in day care centers. This may be due to children attending day care centers or nursery frequently carries antibacterial resistant organisms in their nasopharynx, leading to acute otitis media that may be refractory to antibacterial treatment.

Concerning total knowledge score of the studied sample regarding otitis media. The current study showed that more than three fifths of the studied mothers had good total knowledge, while few of them had poor total knowledge post intervention. This result might be due to the effectiveness of nursing intervention and the experience that gained from group discussion during the sessions.

Regarding total practices score of the studied sample. This study revealed that; more than three quarter of the studied mothers had satisfactory total practices regarding caring of their preschool children with otitis media post intervention. These findings were in agreement with Mohamed (2019) who founded that three quarters of the studied mothers had satisfactory total practices. This might be due to the positive effect of health nursing intervention on mother' practices.

Regarding correlation between total knowledge and total practices among studied mothers. The current study revealed that there were a highly statistically significant correlation between total practices and total knowledge post intervention. These findings were in consistent with Mohamed (2019) who revealed that there were a positive relation between total scores of mothers' knowledge and their practices regarding care of their children suffering from otitis media.

\section{Conclusion}

More than three fifths of the studied mothers had good total knowledge regarding otitis media, few of them had poor total knowledge and more than three quarters of them had satisfactory total practices regarding care of their children with otitis media at post intervention implementation compared to less than half at pre intervention.

There were statistically significant relations between the studied mothers total knowledge score regarding otitis media and their educational level, income and residence pre-post intervention. In addition there were statistically significant relations between the studied mother's total practices score regarding caring of their children with otitis media and their educational level, occupation, income and residence pre-post intervention. There were highly statistically significant 
correlation between the studied mothers' total practices and total knowledge during pre and post intervention.

\section{Recommendations:}

- Arabic booklet that including information about otitis media and mothers' care for their preschool children should be made available in all outpatient hearing clinics.

- Continuous nursing intervention for mothers regarding care of their preschool children with otitis media should be performed regularly at the outpatient hearing clinics in order to improve their knowledge and practices.

\section{References}

Abdelazim, M., Zaghloul, A., \& Elbakly, M. (2020). Prevalence of Otitis Media with Effusion in Children of Damietta Governorate (Egypt). International Journal Of Medical Arts.2(2). https:// ijma. Journals .ekb. eg/article_74828.html

Abraham, S. (2019). Improving the Body Image, Eating Attitudes, and Behaviors of Young Male and Female: Anew Educational Approach, International Journal of Eating Disorders, 28(1), Pp.43-57, Accessed on 8 Jan 2020, Available at: https//www.researchgat.n

Busom, J., Costas, O., Agusti, M., Grant, N., Kirchner, H. (2021). Evidence of otitis media and mastoiditis in a Medieval Islamic skeleton from Spain and possible implications for ancient surgical treatment of the condition. International Journal of Paleopathology. 32(2). https://www.sciencedirect.com/ science/article/pii/S1879981720300553

Byeon, H. (2019). The association between allergic rhinitis and otitis media: A national representative sample of in South Korean children. Scientific Reports Journal.4(1). https:/ /www.nature . com/ articles /s41598018-38369-7\#Sec2

Elsayed, D. (2018). Assessment of mothers' knowledge and practices regarding care of their children with otitis media, Faculty of Nursing, Tanta University, Pp.64-81.

El-tohamy, M. (2019). Assessment of mother's practice of knowledge about care of their children suffering from otitis media with the view to develop health education module. Master thesis. Faculty of Nursing. Mansoura University. Pp. 54-80

Espahbodi, M., Samuels, T., Yan, K., Chun, R. (2020). Analysis of Inflammatory Signaling in Human Middle Ear Cell Culture Models of Pediatric Otitis Media. Laryngoscope Journal. 131(2). Available at: https://onlinelibrary.wiley.com/doi/full/10.10 02/lary.28687.

Hardani, A., Esfandabadi, F., Delphi, M., Samir, M., \& Abdollahi, F. (2020). Risk Factors for Otitis Media in Children Referred to Abuzar Hospital in Ahvaz: A Case-Control Study. Cureus Journal. 12(8). Available at: https:// www. Ncbi .nlm. nih. gov/ pmc/ articles /PMC 7489764 /. Accessed on 23/12/2020.

Kono, M., Ukushima, K., Kamide, Y., Kunimoto,M., Matsubara, S. (2021). Features predicting treatment failure in pediatric acute otitis media. Journal of Infection and Chemotherapy. 27(1). Pp 19-21. Availableat:https://www.sciencedirect.com/sc ience/article/pii/S1341321X20302737

Mohamed, R. (2019). the impact of an educational program for mothers of children with otitis media on the prevention of its recurrence at Zagazige University Hospital. Doctorate thesis. Faculty of Nursing. Mansoura University. Pp.37-86. 
Saad, K., Abdelmoghny, A., Abdelrahman, Y., Gad, E., Elhoufey, A. (2020). Prevalence and associated risk factors of recurrent otitis media with effusion in children in Upper Egypt. World Journal of Otorhinolaryngology-HeadandNeck Surgery . Availableat:https://www.sciencedirect.com/sc ience/article/pii/S2095881120301219\#!.Acces sed on 30/8/2020. 45(1).

Ti Tikaram, A., Chew, Y., Chong, A., \& Prepageran, N. (2019). Prevalence and risk factors associated with otitis media with effusion in children visiting tertiary care center in Malaysia. International Medical Journal of Malaysia, 11(1), Pp37-40, Available at: https://journals.iium.edu.my/kom/index.php/ imjm/article/view/545

World Health Organization (WHO). (2019). Health Education, Accessed on 16 May 2020, Available at: https//www.givingwhatwecan. org/res 
التذخل التمريضي لتحسين رعاية الأمهات لأطفالهن المصابين بالتهاب الأذن الوسطى في مرحلة ما قبل المدرسة

بسمه محمود أحمد - هناء عبد الجواد عبد المجيد - أمينة عبد الر ازق محمود

يعد التهابات الأذن الوسطى من الأمر اض الأكثر شيوعا بين الأطفال الصغار على مستوى العالم. و على الرغم

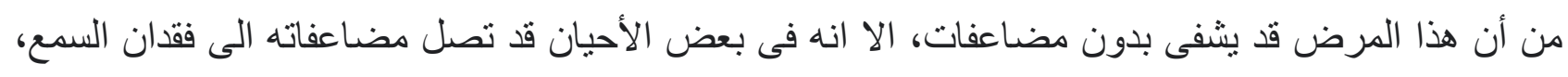

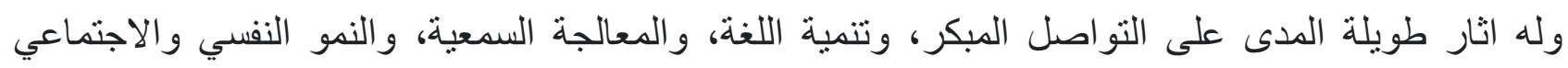

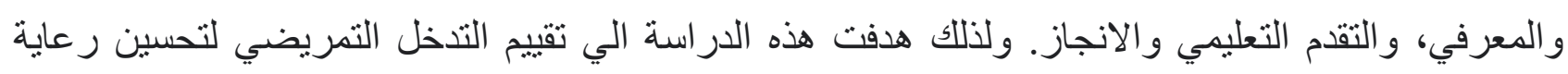
الأمهات لأطفالهن المصابين بالتهاب الأذن الوسطى في مرحلة ما قبل المدرسة. وقد أجريت الدراسة في العيد العيادة

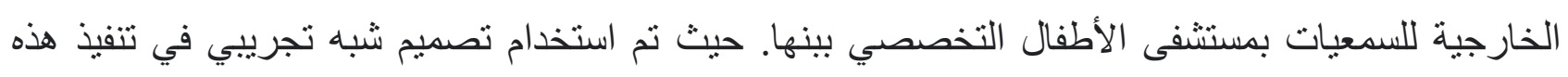

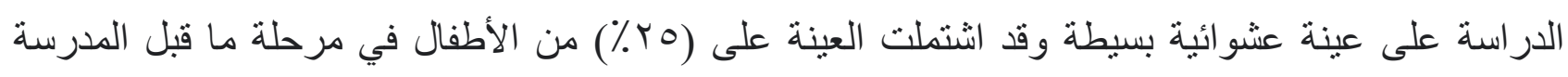

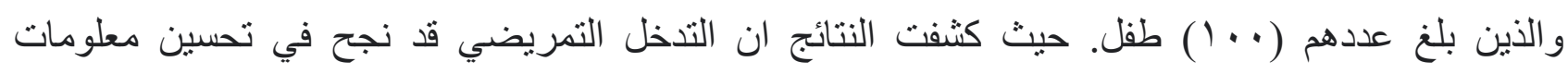

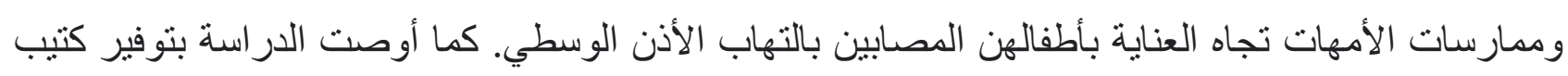

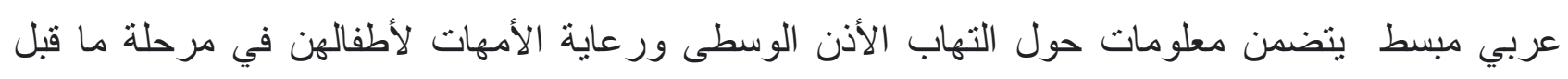
المدرسة في جميع عيادات السمع الخارجية. 